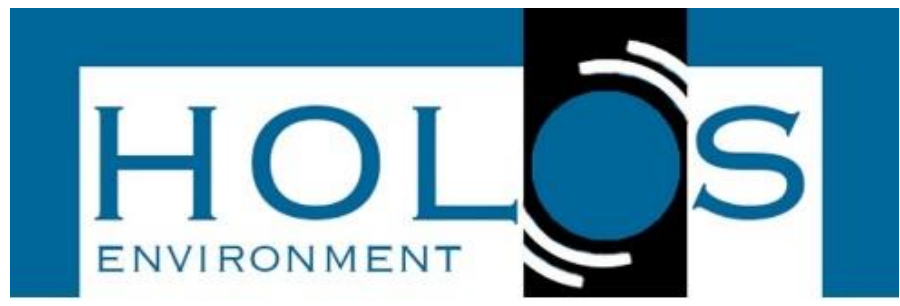

\title{
MINIMIZAÇÃO DO CONFLITO NA GESTÃO DO TERRITÓRIO POR MEIO DO EMPREGO DA LOGICA BOOLEANA E CRITÉRIOS GEOAMBIENTAIS PARA DEFINIÇÃO DE ÁREAS FAVORÁVEIS À IMPLANTAÇÃO DE ATERRO SANITÁRIO: ESTUDO DE CASO NO MUNICÍPIO DE ITABIRA - MG
}

\section{MINIMIZATION OF CONFLICT IN TERRITORY MANAGEMENT THROUGH LOGICA BOOLEANA EMPLOYMENT AND GEOENVIRONMENTAL CRITERIA FOR THE DEFINITION OF AREAS FAVORABLE TO LANDFILL IMPLANTATION: A CASE STUDY IN THE MUNICIPALITY OF ITABIRA - MG}

\author{
Gabrielle Loubach Miranda'; Júlia Brito Simião1; Pedro Henrique Santos Abreu; Eli- \\ ane Maria Vieira ${ }^{1}$
}

Artigo recebido em: 25/08/2019 e aceito para publicação em: 21/11/2019. DOI: http://dx.doi.org/10.14295/holos.v19i4.12353

\begin{abstract}
Resumo: A implantação de um aterro sanitário é foco de diversos conflitos em função dos impactos que este causa ao meio, tanto sociais quanto ambientais, neste sentido o presente estudo objetiva selecionar áreas favoráveis à implantação de um aterro sanitário de forma a minimiza-los, tendo como área de estudo o município de Itabira, Minas Gerais. A determinação das áreas foi fundamentada em critérios de restrições e aptidões com base nas recomendações da Norma NBR 13.896 de 1997. Foi empregado o Sistema de Informações Geográficas (SIG) - ArcGis para aplicação da lógica tendo como características restritivas declividade, distância dos recursos hídricos, distância de vias, distância de núcleos populacionais, distância da mina de ferro e unidades de conservação, sendo que as áreas inaptas receberam valor 0 , e as áreas favoráveis receberam o valor 1 . O resultado final, com a multiplicação de todos os mapas, gerou um mapa final de favorabilidade, adotando um critério de distância, que classifica as áreas como inaptas, restritas, moderadas ou favoráveis a construção de um aterro sanitário no município. Um grande ganho da metodologia empregada é o fato de se minimizar a subjetividade na definição dos locais, visto que se trabalha com fatores que podem ser delimitados espacialmente. $\mathrm{O}$ fato de apresentar os resultados em níveis de favorabilidade proporciona ao tomador de decisões, publico ou privado, maiores opções de locais para que se possa implantar o aterro, ademais, a metodologia aplicada pode ser utilizada tanto em outros municípios quanto a consócios destes em função da facilidade de implementação mesmo em grandes regiões territoriais.
\end{abstract}

Palavras-chave: Resíduo sólido urbano. Favorabilidade. Geoprocessamento.

Abstract: The implementation of a sanitary landfill is the focus of several conflicts due to the impacts
that this cause to the environment, both social and environmental, in this sense the present study aims
to select areas favorable to the implantation of a sanitary landfill in order to minimize them, area of study
is the municipality of Itabira, Minas Gerais. The determination of the areas was based on criteria of
restrictions and aptitudes based on the recommendations of the norm NBR 13.896 of 1997 . The Geo-
graphic Information System (GIS) - ArcGis was used to apply the logic having as restrictive characteris-
tics slope, distance of water resources, distance of roads, distance of population centers, distance from
the iron mine and conservation units, and the unfit areas received a value of 0 , and favorable areas
received a value of 1 . The final result, with the multiplication of all maps, generated a final map of favo-
rability, adopting a distance criterion, which classifies the areas as inapt, restricted, moderate or

1 Universidade Federal de Itajubá (UNIFEI), Itabira, MG. E-mails: (loubachgabi@gmail.com, apjsimiao@gmail.com, pedro abreu@live.com, elianevvv@yahoo.com.br) 
favorable to the construction of a sanitary landfill in the municipality. A great gain of the methodology used is the fact of minimizing the subjectivity in the definition of the places, since one works with factors that can be delimited spatially. The fact of presenting the results at levels of favorability gives the decision maker, public or private, greater options of locations for the landfill can be implemented, in addition, the applied methodology can be used in other municipalities as well as the conspiracy of these in function ease of implementation even in large territorial regions.

Keywords: Urban solid waste. Landfil. Geoprocessing.

\section{INTRODUÇÃO}

Sabe-se que nas últimas décadas vem aumentando cada vez mais a população mundial e com isso a quantidade de resíduos gerados. Assim, os resíduos sólidos urbanos tem movido grandes debates acerca dos seus possíveis tratamentos e disposição final.

Contudo o crescimento da geração de resíduos não tem acompanhado o crescimento populacional, segundo Abrelpe (2015), houve um crescimento de 2,9\% na geração comparando-se o ano de 2014 e 2013, com um total de 78,6 de toneladas de Resíduos Sólidos Urbanos (RSU), enquanto o crescimento populacional brasileiro foi de apenas 0,99\% entre os anos de 2014 e 2013.

Outro fato levantado pelos autores é que do total gerado de RSU, 90,6\% foram coletados no referido período, demonstrando que o Brasil caminha para a universalização da coleta, porém destes apenas $58,3 \%$ foram destinados adequadamente em aterros sanitários.

As projeções demográficas realizadas pelo Instituto Brasileiro de Geografia e Estatística (IBGE) para o período de 2000 a 2060 indicam que em 2042 a população brasileira atingirá seu máximo, com aproximadamente 228,4 milhões de habitantes (IBGE, 2013). Considerando a produção per capita de resíduos atual, cerca de 1,04 $\mathrm{kg} / \mathrm{hab} / \mathrm{dia}$, no ano de 2042 serão gerados mais de 31,6 trilhões de toneladas de RSU, porém, tem-se observado que a taxa de produção de resíduos per capita no país tem crescido em proporções maiores do que a taxa de crescimento da população (ABRELPE, 2015). Assim, é provável que o volume gerado seja superior a este.

A destinação inadequada destes resíduos causa uma série de problemas como: contaminações do solo e das águas subterrâneas, que variam de acordo com a quantidade e os tipos de resíduos que são depositados (GONÇALVES, 2016).

Assim, solucionar a problemática dos resíduos sólidos tem sido prioridade para os gestores atuais, mas também um dos grandes desafios. 
Desde a Conferencia Rio 92, o tema tem se mostrado prioritário, tanto para países ricos quanto para os mais pobres, visto que este também contribui direta ou indiretamente com o aquecimento global e as mudanças do clima.

A Lei 12.305 de 2010, coloca em vigor no Brasil a Política Nacional dos Resíduos Sólidos (PNRS) englobando uma série de instrumentos que atuando em conjunto pode permitir que o país avance na solução do problema causado pelos resíduos sólidos. Nessa lei são estabelecidas as ordens de prioridade sendo a primeira a não geração, seguindo pela redução do volume gerado, pela reutilização, reciclagem, tratamento dos resíduos sólidos e em ultima análise a disposição final ambientalmente adequada dos rejeitos.

De acordo com a PNRS todas as ações anteriores à disposição final, devem ser colocadas em prática antes de se pensar na disposição em um aterro sanitário. Porém, ainda há casos de disposição em lixões e aterros controlados, sem passar pelas etapas anteriores.

Também com a PNRS estabelece-se a necessidade da extinção dos lixões e aterros controlados devido à falta de preocupação ambiental desses dois empreendimentos e coloca o aterro sanitário como alternativa para essa substituição.

Segundo Felicori et al. (2016), o aterro sanitário consiste na disposição de resíduos em uma área impermeabilizada, sendo recoberto e compactado com camadas sucessivas de solo.

De forma geral ao se adotar um aterro sanitário pretende-se gerenciar o rejeito no sentido de controlar a migração de gases e efluentes gerados pela decomposição da matéria orgânica contida e de evitar o seu contato com águas de precipitação e subterrâneas (GOMES et al., 2017).

Entretanto, um problema no que se refere aos aterros sanitários é a sua vida útil. Segundo Marchi (2015), estes são projetados para uma vida útil superior a 10 anos, prevendo-se ainda a sua monitorização alguns anos após o seu fechamento, sendo projetados e construídos em conformidade com a legislação vigente, após estudos de impacto ambiental (EIA) e processo de licenciamento.

Um dos maiores problemas em cidades densamente urbanizadas, especialmente nas Regiões Metropolitanas, é a falta de locais apropriados para dispor os resíduos adequadamente, tanto na construção do primeiro aterro, quanto nos subsequentes após atingir a capacidade de suporte deste. 
Contudo este problema não é exclusivo de grandes centros, visto que grande parte dos fatores que tornam um local inapropriado também estão presentes em cidades de pequeno e médio porte, como existência de áreas ambientalmente protegidas e aos impactos de vizinhança gerados pelas áreas de disposição. Por isso cada vez mais tem-se a necessidade de encontrar áreas apropriadas para a construção de aterros sanitários.

Em decorrência disso, existe a necessidade de estabelecer condições de exigências mínimas para a implantação desse tipo de empreendimento. A NBR 13896/97 "Aterros de resíduos não perigosos - Critérios para Projeto, Implantação e Operação", tem como um de seus objetivos definir parâmetros mínimos exigíveis para o projeto, implantação e operação de um aterro sanitário.

Além da NBR 13896/97 existe todo um aparato legal para implantação de um empreendimento como o aterro sanitário. A nível federal podemos citar: Resolução CONAMA 01 / 1986; Resoluções CONAMA 05 / 1988 e 237 / 1997; Resolução CONAMA 308 / 2002 (LINO, 2007). A nível estadual, pode-se citar a Lei no 18.031/2009 "Política Estadual de Resíduos Sólidos" e outros decretos que acrescentam dispositivos a essa lei, para o estado de Minas Gerais.

De acordo com a NBR 13896/97 a seleção de uma área para implantação de um aterro sanitário necessita de estudos para que o empreendimento e a disposição de resíduos naquela área não ofereçam riscos ao meio ambiente, à saúde pública, bem como se minimize os gastos e que os interesses da comunidade sejam respeitados.

Selecionar uma área para alocar a obra do aterro sanitário é um processo complexo que envolve o meio biótico, abiótico, além do socioeconômico. Com o objetivo de facilitar esse processo, diversos pesquisadores vêm desenvolvendo nos últimos anos métodos para esse procedimento, em sua maioria incentivado pela aplicabilidade dos sistemas de informações geográficas (SIGs), como os trabalhos desenvolvidos por sobressaindo os produzidos por Ohri e Singh (2013), Isalou et al. (2013), Rezaeimahmoudi et al. (2014), Khan e Samadder (2014), Beskese et al. (2015) e Bahrani et al. (2016).

Neste sentido, o presente estudo tem como objetivo indicar um ou mais locais com melhor adequabilidade para construção de um aterro sanitário a partir de uma análise feita utilizando o software ArcGis dentro dos parâmetros mínimos exigidos pela NBR 13896/97, tendo como área de estudo o município de Itabira (MG). 


\section{MATERIAL E MÉTODOS}

A área de estudo está localizada na latitude 19 37' 09" S e longitude: $43^{\circ} 13^{\prime}$ 37" O (figura 1). Situada aproximadamente a $110 \mathrm{~km}$ da capital Belo Horizonte, Itabira ocupa uma área de 1253,704 km² e uma população de 109.783 habitantes. Estimativas mostraram que em 2017 a população poderia chegar a 119.285 habitantes. (IBGE, 2010).

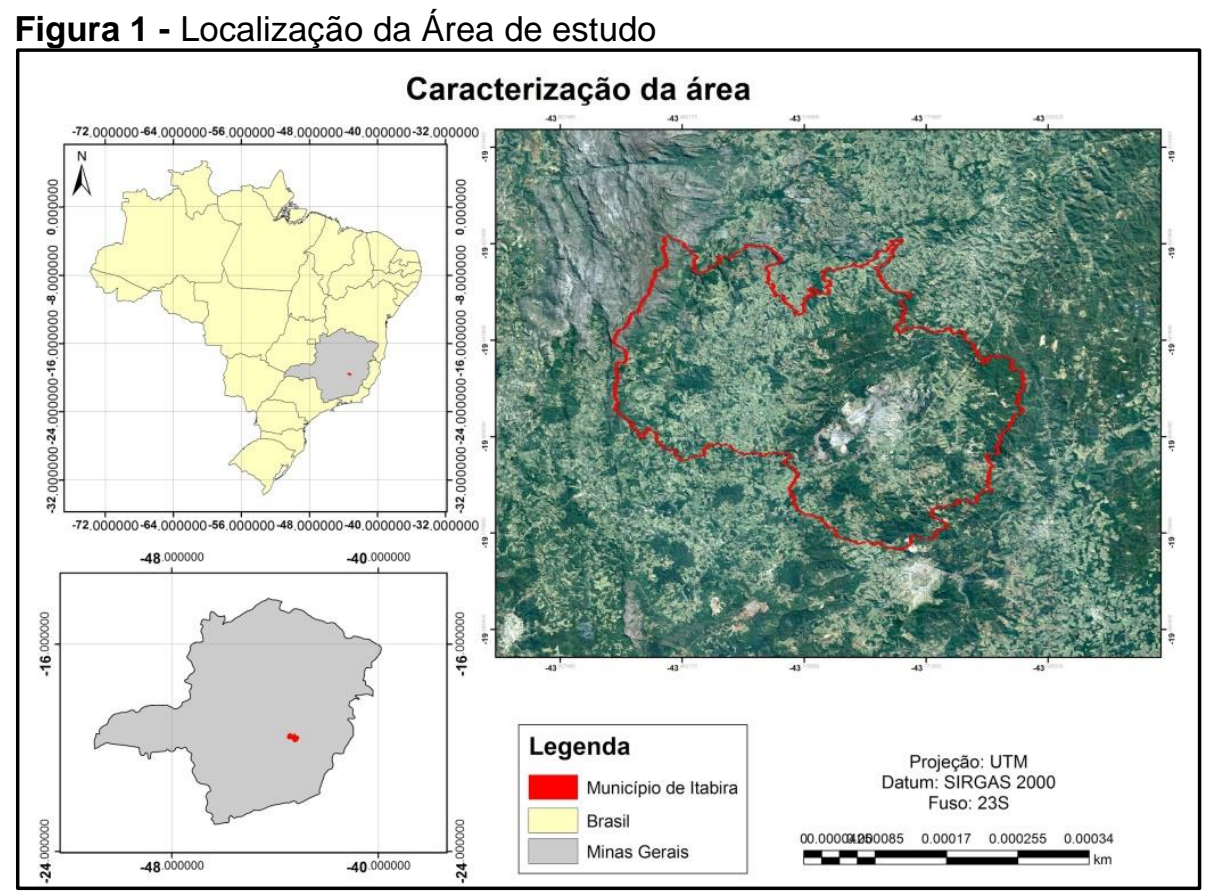

Fonte: Autores deste trabalho

Itabira possui dois distritos (Ipoema e Senhora do Carmo) e se destaca pela atividade mineradora realizada pela empresa Vale. Sua economia ainda é muito dependente das operações da Vale e movimentações relacionadas a esta, o que consequentemente atrai mão de obra externa, aumentando a população local. Devido ao evidente esgotamento das minas exploradas na cidade, viu-se necessária a diversificação da economia local (Revista Brasil Mineral, 2013). Tendo como objetivo diversificar a economia, mostrou-se viável a implantação de um polo tecnológico, a começar pela Universidade Federal de Itajubá (Unifei). A instituição pública federal iniciou suas atividades na cidade há 10 anos e desde então recebe anualmente muitos estudantes de outros municípios. A permanência dos estudantes e daqueles que trabalham no campus e vieram de outras cidades movimenta e nutre a economia local. 
Um fator relacionado ao aumento dessa população são os resíduos gerados, resultante do consumo de produtos e serviços.

$O$ aterro sanitário de Itabira $(\mathrm{MG})$ foi construído pela mineradora Vale e foi inaugurado em novembro de 2012. Durante o ano de $2014 \mathrm{o}$ aterro passou por uma readequação, onde foi construída uma nova célula com impermeabilização do solo, drenagem de chorume e gás, visando minimizar os impactos ambientais e socioeconômicos além de aumentar a vida útil do aterro para cerca de 15 a 20 anos (PREFEITURA DE ITABIRA, 2014). Apesar de estar projetado para ter seu esgotamento próximo aos anos de 2027-2031, estudos para área de implantação, projeto, planejamento, processos licitatórios e construção requerem tempo, fazendo com o que o município de Itabira tenha, desde já, que pensar em novas áreas para disposição final de seus resíduos.

\subsection{Métodos}

O presente trabalho foi desenvolvido em ambiente SIG empregando a análise multicritérios e a álgebra booleana aos planos de informações, estas metodologias consistem em uma multiplicação dos planos de entrada como mapas temáticos elaborados a partir de diferentes critérios pré-estabelecidos pela NBR 13896/97 por meio de operadores condicionais que geram possíveis áreas a serem estudadas, conforme metodologia adotada por Amaral e Lana (2017).

A álgebra booleana é uma ferramenta lógica que classifica os elementos com os seguintes critérios: AND (interseção), OR (união), NOT (negação) e XOR (exclusão).

O resultado dessa análise dá-se de forma binária, 0 e 1 não favorável e favorável, respectivamente, partindo do suposto em que todos os critérios possuem o mesmo peso e não existe uma condição de talvez. E há também a análise multicritério que age em conjunto com a álgebra booleana fazendo um estudo de diversos critérios e de diferentes possibilidades de resultados, esse método auxilia na deliberação de decisões.

$\mathrm{Na}$ realização deste trabalho foi adotado apenas o operador de lógica booleana AND, ou seja, a intersecção de uma área favorável com uma área não favorável resulta em uma área não favorável, mantendo desta forma a restrição à implantação de aterros sanitários, mesmo que apenas um plano de informação atribua restrição ao local analisado. 
Foram trabalhados os critérios geoambientais: Declividade, Distância aos cursos d'água, Distância à núcleos urbanos e Unidades de conservação.

Foi realizada uma combinação entre todos os mapas temáticos, no mapa resultante da análise da álgebra booleana as áreas que receberam nota 0 foram consideradas como não favoráveis (ou restritas), sendo descartadas da seleção. As áreas que obtiveram nota 1 foram selecionadas para classificação de acordo com a adequabilidade em razão da distância da fonte de geradora de resíduos, recebendo a classificação favorável, moderada ou restrita.

A figura abaixo exemplifica o fluxograma seguido para obtenção do mapa final para seleção da melhor ou das melhores áreas para implantação de um aterro sanitário.

Figura 2 - Diagrama de Venn e as aplicações de operadores de lógica booleana

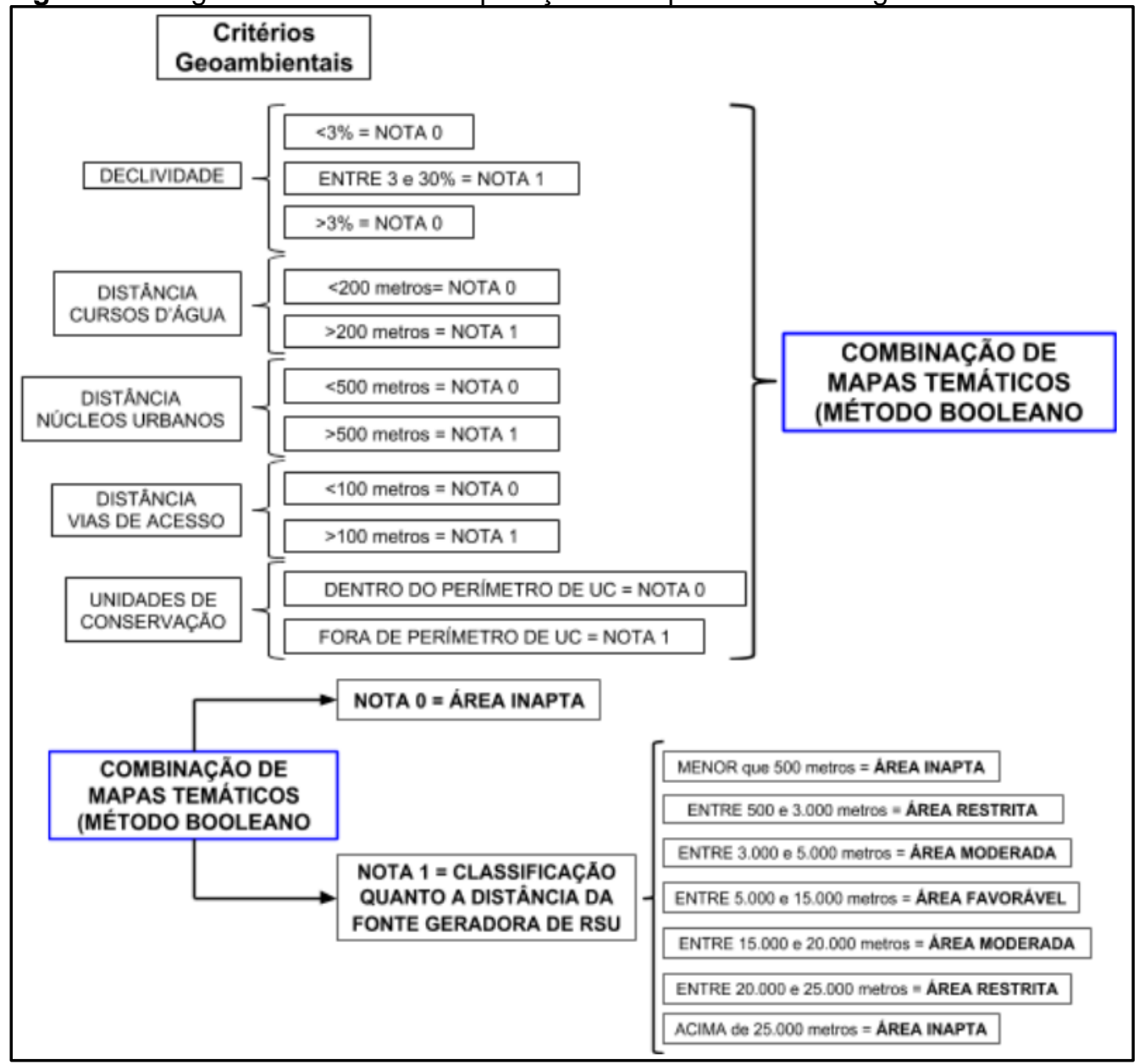

Fonte: Amaral e Lana (2017)

Em relação a critérios ambientais e de uso e ocupação do solo foram usadas para classificação da área mais apropriada: o limite do município de Itabira, as estradas que percorrem a cidade, as bacias e sub-bacias hidrográficas, declividade e áreas de proteção permanente (APP). 


\section{RESULTADOS E DISCUSSÃO}

A NBR 13.896 (ABNT, 1997) estabelece normas para realização de projetos, construção e operação de aterros sanitários. De acordo com ela, algumas considerações técnicas devem ser feitas para avaliação de adequabilidade de um local:

Topografia - é considerado um fator determinante nas obras de terraplanagem de construção e instalação. Na figura abaixo tem-se representada a declividade do município de Itabira.

Figura 3 - Mapa de declividade do município de Itabira

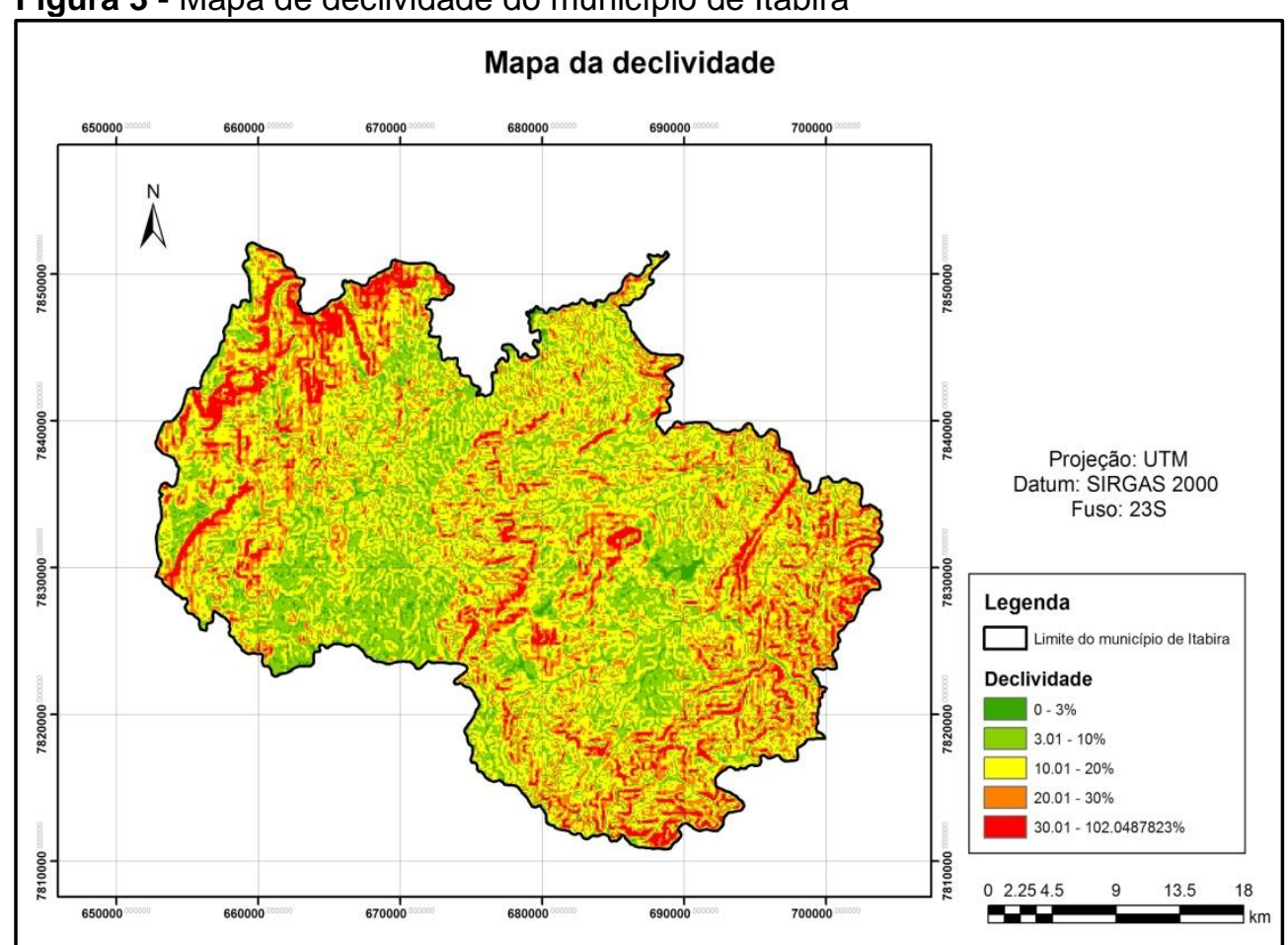

Fonte: Autores deste trabalho

De acordo com a legislação, é recomendado a escolha de locais com declividade superior a $1 \%$ e inferior a $20 \%$. A figura 4 mostra o mapa de declividade do município de Itabira reclassificado, o qual foi distribuído notas de acordo com a favorabilidade do relevo. Terrenos com declividade menor que $3 \%$ e maior que $20 \%$ receberam nota 0 e foram considerados inaptos para construção do aterro. Já os terrenos com declividade entre $3 \%$ e $20 \%$ receberam nota 1 , sendo considerados como favoráveis para construção do aterro, já que alguma declividade pode indicar a presença de material de empréstimo e facilitar a construção de trincheiras. 
Figura 4 - Reclassificação do mapa de declividade do município de Itabira

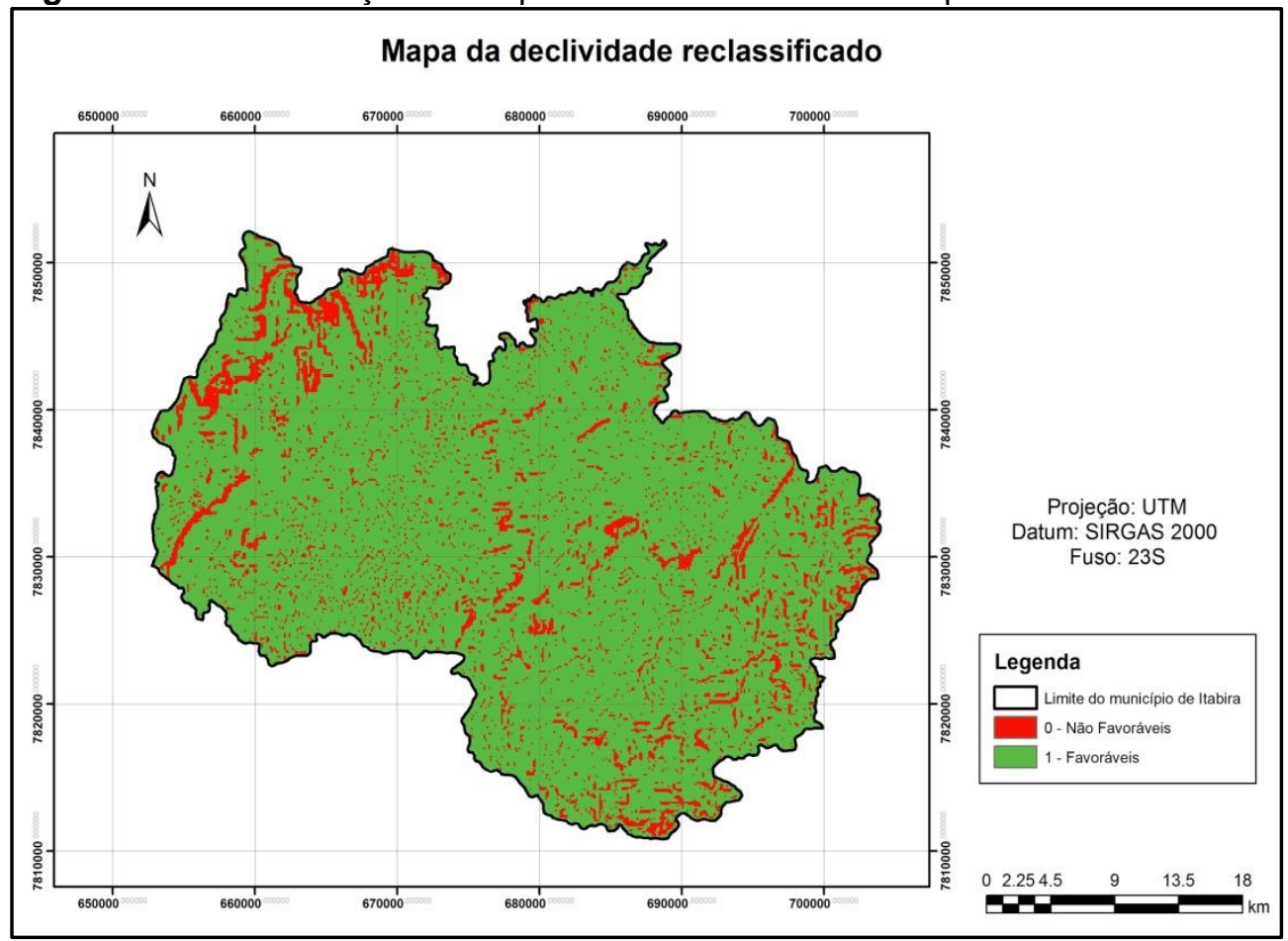

Fonte: Autores deste trabalho

Recursos hídricos superficiais - No local onde é implantado um aterro sanitário é imprescindível que haja a impermeabilização do solo e implantação de sistemas de drenagem para todos os líquidos gerados, evitando assim possíveis contaminações. Contudo, mesmo adotando-se estas medidas deve-se resguardar uma distância mínima, conforme a norma NBR 13.896 (ABNT, 1997), a distância mínima dos cursos d'água adotada deve ser de 200 metros.

Seguindo os critérios de seleção de áreas, é ilustrado na figura a seguir a faixa de influência dos cursos d'água do município de Itabira. Terrenos localizados à uma distância de até 200 metros de qualquer curso d'água receberam nota 0 , considerados inaptos para construção do aterro. E os terrenos localizados à uma distância maior que 200 metros receberam nota 1 e foram selecionados para classificação de favorabilidade.

Distância mínima de núcleos populacionais - é recomendado que a distância limite da área útil do aterro aos núcleos populacionais seja superior a 500 metros, conforme a norma NBR 13.896 (ABNT, 1997). Esta distância visa reduzir os transtornos causados à população pela instalação do aterro, como odores, ruídos e desvalorização imobiliária. A imagem abaixo mostra uma área de influência dos centros urbanos de 500 metros, em que terrenos situados a essa distância receberam nota 0 e os 
terrenos com distância superior a 500 metros dos núcleos populacionais receberam nota 1 para favorabilidade.

Figura 5 - Mapa da faixa de influência da rede hidrográfica do município de Itabira.

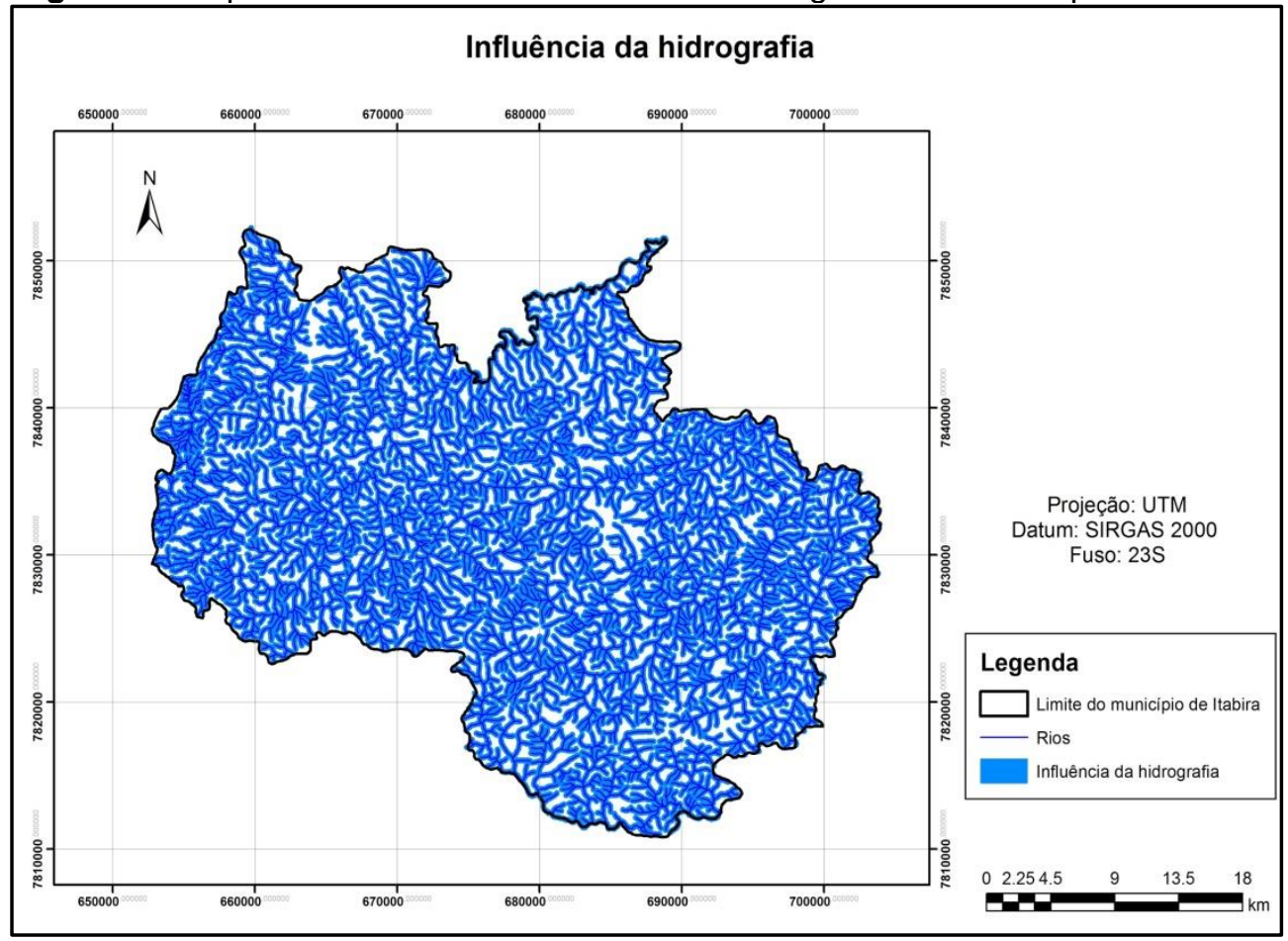

Fonte: Autores deste trabalho

Figura 7 - Mapa de faixas de influência dos centros populacionais

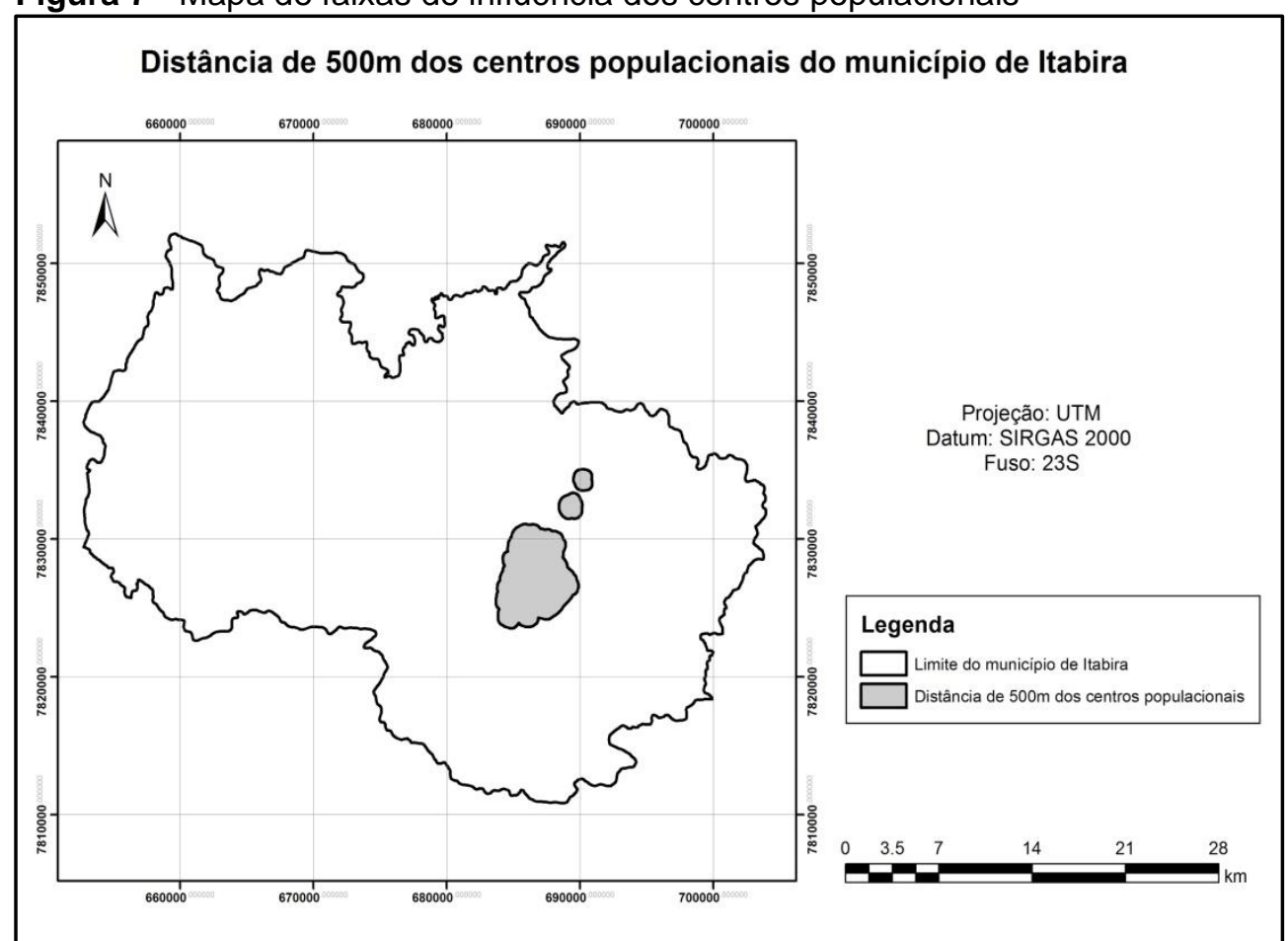

Fonte: Autores deste trabalho 
Acessos - é um fator evidentemente importante por ser utilizado durante toda a operação. Locais com fácil acesso e vias em bons estados de conservação são mais indicados para assegurar o transporte de resíduos.

Distância de vias - deve ser respeitado uma distância mínima de 100 metros de rodovias e estradas, a fim de se reduzir alguns impactos ambientais, ruídos e odores.

A figura a seguir ilustra as faixas de influência de 100 metros das principais vias de acesso rodoviário do município de Itabira, sendo consideradas rodovias pavimentadas e estradas secundárias.

Os terrenos situados dentro das faixas de influência das estradas rodoviárias e importantes vias receberam nota 0 e foram considerados inaptos. Os outros terrenos receberam nota $1 \mathrm{e}$ foram selecionados para classificação quanto à favorabilidade.

Figura 8 - Mapa de faixas de influência de vias e acessos do município de Itabira

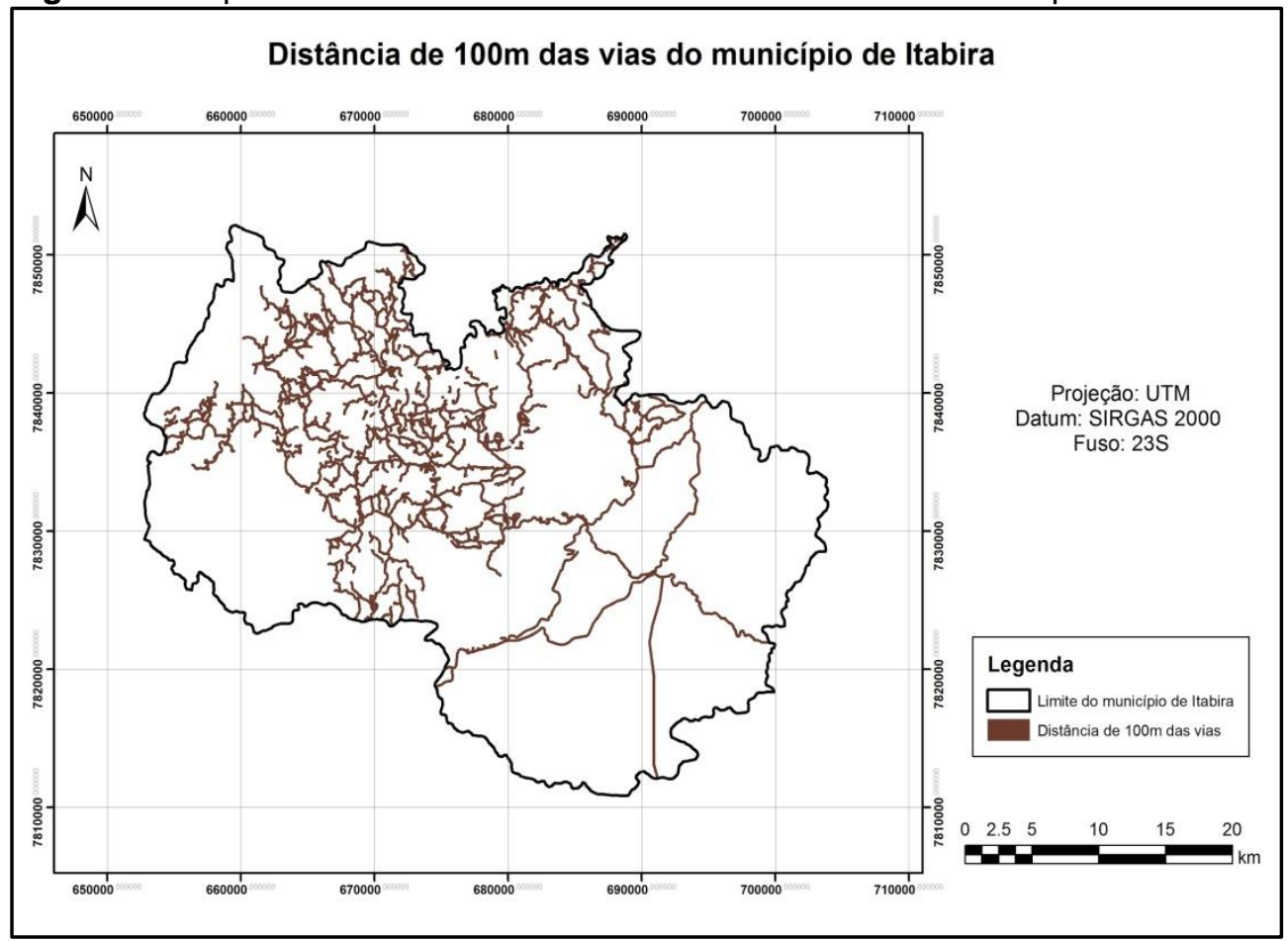

Fonte: Autores deste trabalho

Julgou-se importante também considerar a ferrovia existente na cidade. Foi usado o mesmo critério da área de influência de $100 \mathrm{~m}$ das rodovias para a ferrovia como mostra a imagem a seguir. 
Figura 9 - Mapa de faixas de influência de ferrovias do município de Itabira

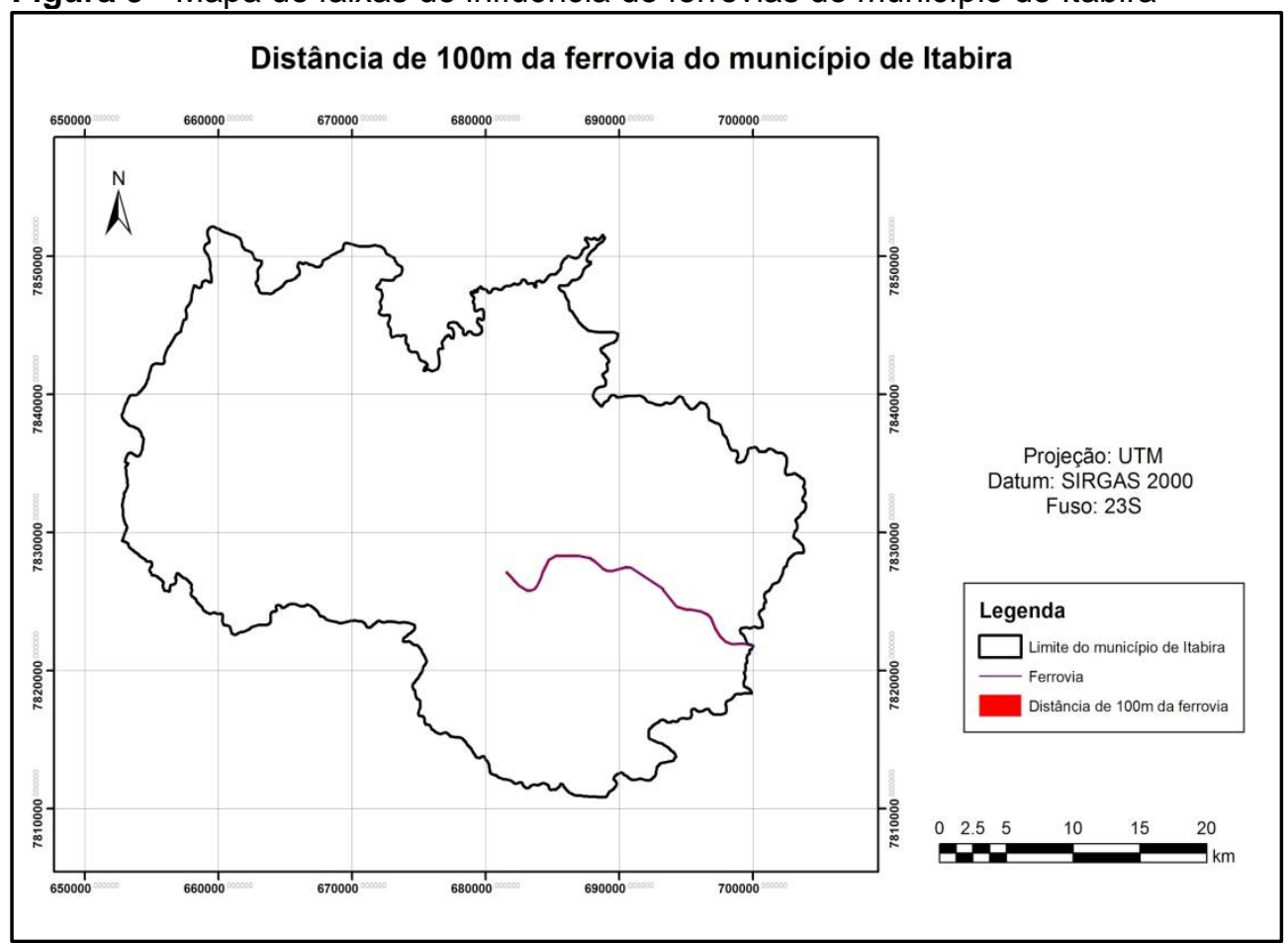

Fonte: Autores deste trabalho

Unidades de conservação - a Lei Federal 9.985 de 2000, define Unidades de Conservação (UC) como espaço territorial e seus recursos ambientais, incluindo as águas jurisdicionais, com características naturais relevantes, legalmente instituída pelo Poder Público, com objetivos de conservação e limites definidos, sob regime especial de administração, ao qual se aplicam garantias adequadas de proteção.

Para instalação de um aterro sanitário é necessário que seja respeitado os locais estabelecidos na legislação ambiental como Unidades de Conservação. A figura abaixo ilustra o mapa de UCs existentes no município de Itabira. As áreas situadas dentro dos polígonos das Unidades de Conservação receberam nota 0 , sendo considerados inaptos. As áreas fora destes polígonos receberam nota 1 e foram selecionadas para classificação de favorabilidade.

Distância da mina de ferro - devido a uma característica marcante do município de Itabira de possuir grande atividade exploratória de mineração, julgou-se necessário considerar a área de mineração para realização dos mapas.

Adotou-se o mesmo critério de distância de centros urbanos para a mina. Foi considerada uma faixa de influência de $500 \mathrm{~m}$ no entorno da mina. As áreas situadas dentro desses $500 \mathrm{~m}$ receberam nota 0 sendo consideradas inaptas. Já as áreas a uma distância maior que $500 \mathrm{~m}$ foram consideradas favoráveis e receberam nota 1 . 
Área disponível e vida útil - é recomendado a escolha de uma área que tenha capacidade suficiente para que o aterro sanitário possa ser projetado objetivando receber resíduos com uma vida útil mínima de dez anos, seguindo a legislação.

Figura 9 - Mapa de Unidades de Conservação no município de Itabira

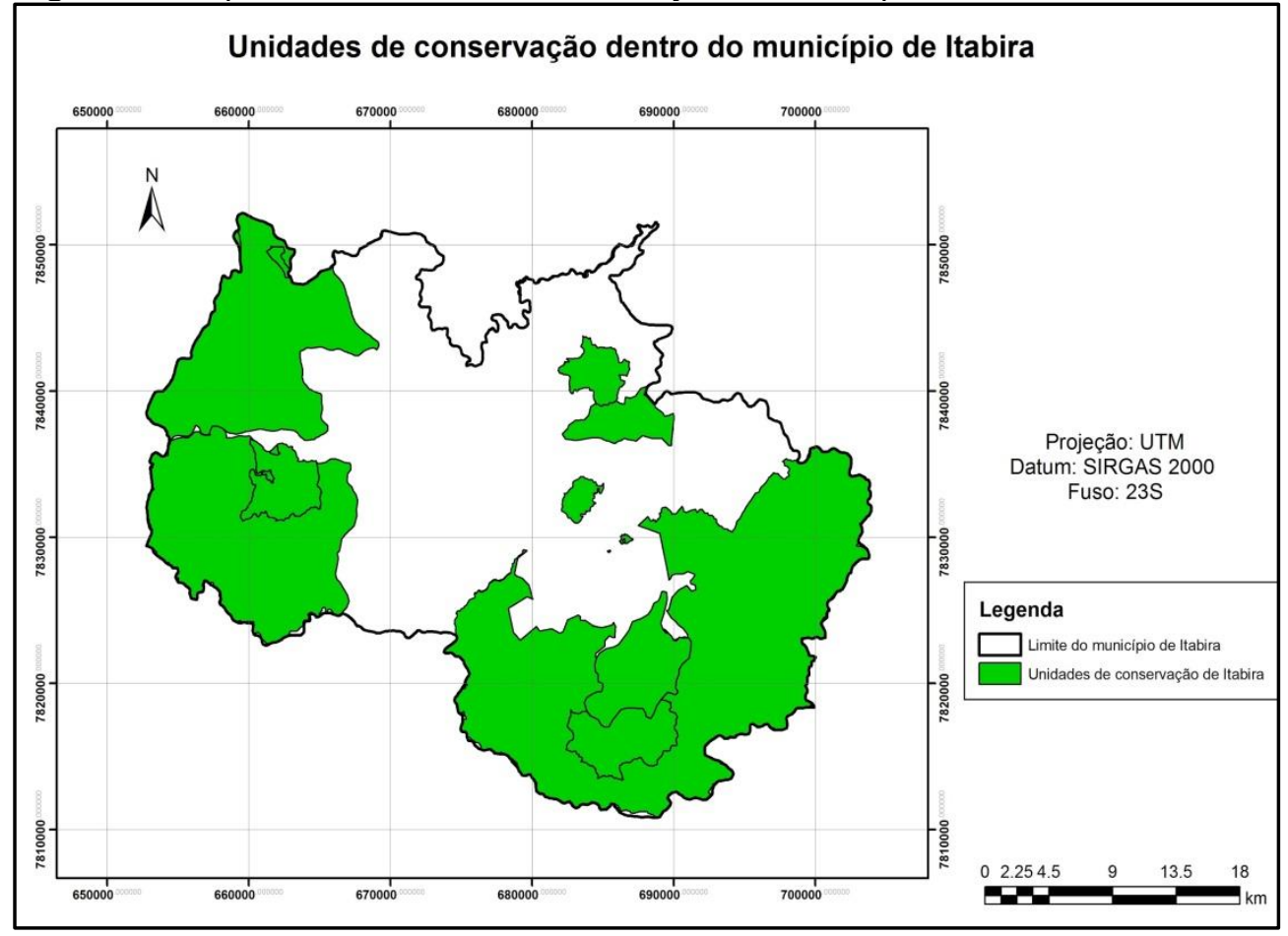

Fonte: Autores deste trabalho

Figura 9 - Mapa de distância da mina de ferro do município de Itabira.

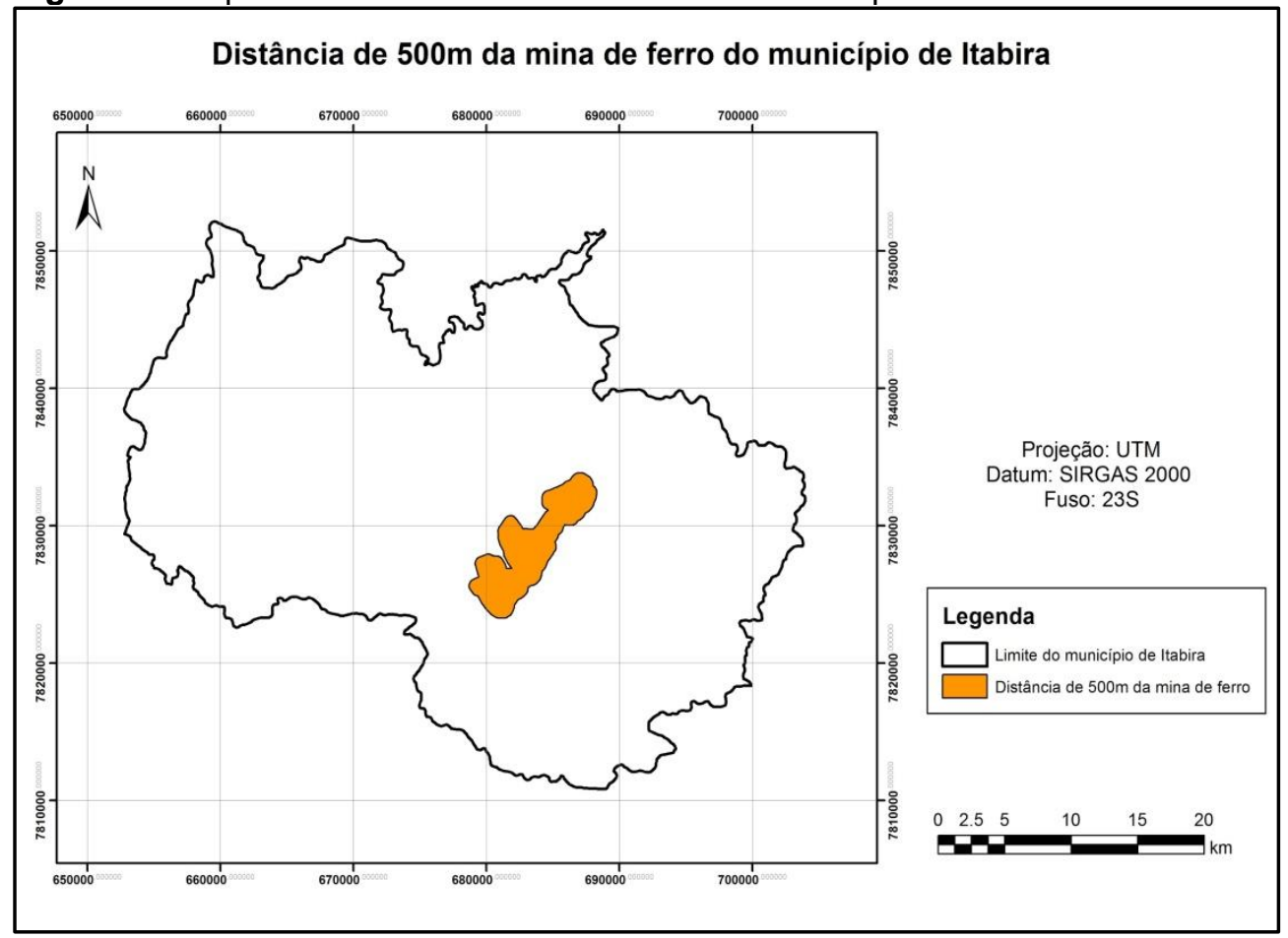

Fonte: Autores deste trabalho 
Mapa Final - para geração do mapa final de favorabilidade foram combinados todos os mapas de critérios ambientais e de uso e ocupação do solo, adotando-se a álgebra booleana. Nessa etapa, foi utilizada a ferramenta "Calculadora de Mapas" do software ArcGis para que fosse feita a multiplicação de todos os mapas expostos acima (que corresponde ao operador booleano AND). Logo as áreas que receberam nota 0 foram excluídas, por serem consideradas inaptas para construção de um aterro sanitário. As outra áreas que receberam nota 1 foram reclassificadas como favoráveis, moderadas e restritas.

A Norma da NBR 13.896 (ABNT, 1997) indica que a distância mínima para construir um aterro sanitário seja maior que 1.000 metros para núcleos populacionais com 200 ou mais habitantes. Deve-se considerar que grandes distâncias implicam no maior gasto com o serviço de transporte e distâncias curtas aumentam os riscos sanitários para a população.

A distância máxima que tem sido adotada nos projetos para seleção da área é de 15.000 metros. Com isso, foi adotado uma faixa mediana entre 5.000 e 15.000 metros dos núcleos urbanos e essas áreas foram classificadas como favoráveis. As áreas situadas entre 15.000 e 20.000 metros e entre 3.000 e 5.000 metros foram classificadas como moderadas. Áreas situadas entre 20.000 e 25.000 metros e entre 500 e 3.000 metros foram classificadas como restritas. $E$ as áreas menores que 500 metros e maiores que 25.000 metros foram classificadas como inaptas.

A figura a seguir ilustra o mapa de favorabilidade para implantação de um aterro sanitário no município de Itabira - MG.

Além disso, foi adicionado ao mapa da classificação das melhores áreas uma consideração em relação às áreas maiores que 45 hectares, visto que o atual aterro de Itabira possui uma área de 42 hectares.

No mapa acima estão classificadas as áreas de acordo com a sua favorabilidade. A área que recebeu a cor preta representa as áreas consideradas inaptas à construção do aterro sanitário; as áreas em laranja representam locais com condições restritas para construção; em azul são as áreas de condições moderadas e em verde áreas com condições favoráveis para a construção do aterro.

Considerando apenas as áreas favoráveis foi realizada a seleção de áreas que possuem uma área igual ou superior a 45 hectares, por apresentarem grande potencial de expansão, considerando que a cidade de Itabira apresenta atualmente uma população de aproximadamente 120 mil habitantes (IBGE, 2018) e para uma cidade de 420 
mil habitantes seria necessária uma área de 20 ha (Benda, 2008). Foram identificadas oito regiões que satisfazem à esta condição.

Figura 10 - Mapa de favorabilidade final

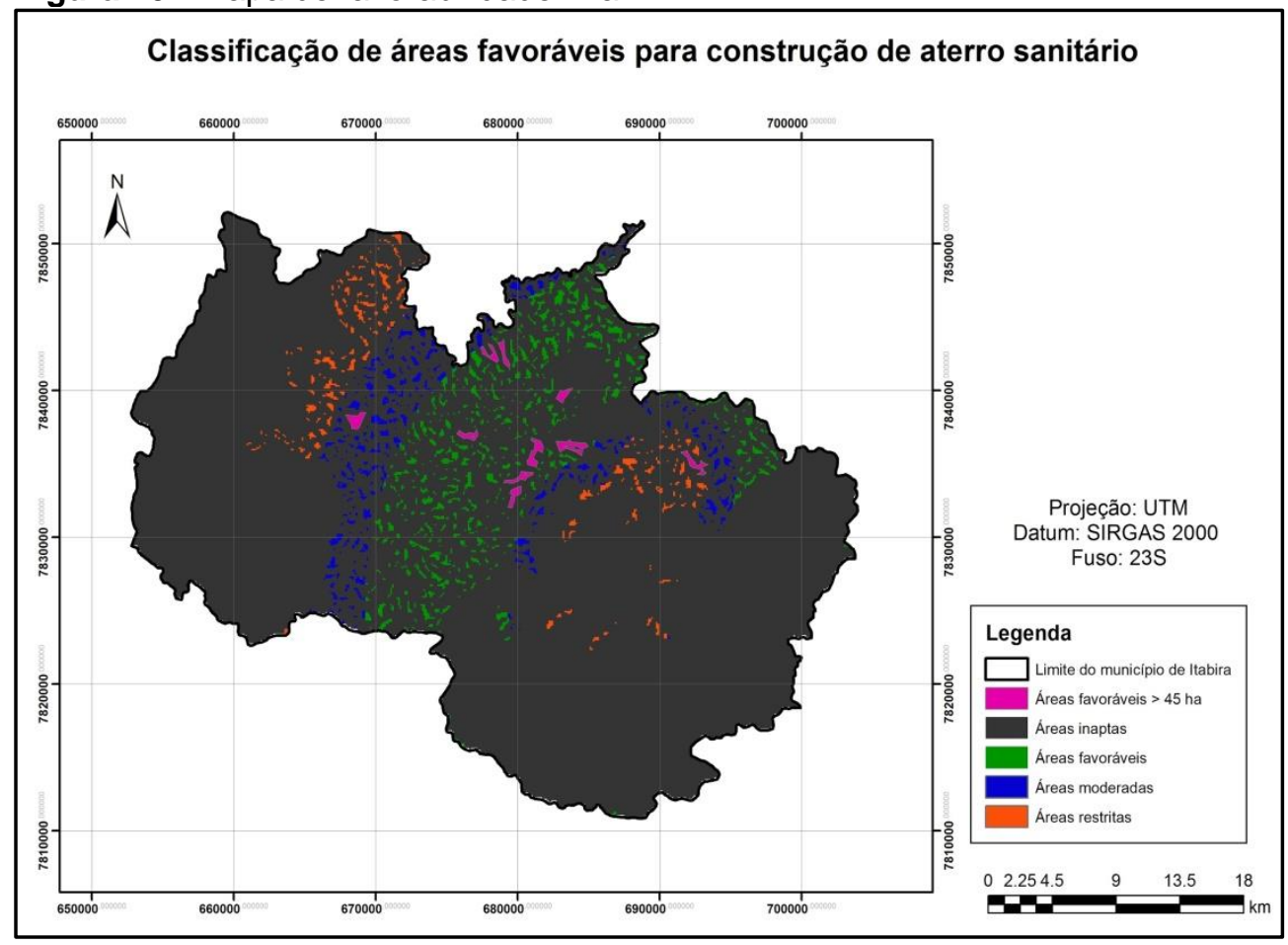

Fonte: Autores deste trabalho

\section{CONCLUSÕES}

É importante destacar que o estudo representa uma identificação preliminar de áreas para a construção de aterros sanitários, visto que as áreas selecionadas como favoráveis e moderadas, podem apresentar outras características que podem inviabilizar a sua utilização para a disposição de resíduos, uso e ocupação do solo, além do fluxo de água subterrânea e permeabilidade do solo, que devem ser analisados (validados) in situ, assim o numero e tamanho das áreas pode reduzir.

Conclui-se que os estudos para selecionar uma área para construção de um aterro sanitário é de grande importância e complexidade considerando todos os parâmetros, normas e legislações a serem seguidos para que os impactos gerados por esse empreendimento sejam minimizados.

A metodologia seguida por este trabalho permitiu que as análises espaciais do município de Itabira fossem facilitadas com a aplicação da ferramenta de 
geoprocessamento, possibilitando uma investigação rápida, porém eficaz, e uma meIhor visualização do município como um todo.

Esse estudo fez uma análise de toda a área disponível dentro do município de Itabira e com base em alguns critérios selecionou as mais aptas para que se construa um aterro, porém cabe salientar que após a escolha do local (ou alguns locais) há a necessidade da realização dos estudos locais: espessura e permeabilidade do solo, aquíferos, vegetação, geomorfologia, entre outros critérios que são.

A aplicação da metodologia também se mostra viável ao se vislumbrar o emprego desta por associações de municípios que embora em termos populacionais sejam considerados de pequeno porte, a extensão territorial destes somadas para a definição do local se torna um grande desafio, contudo ao empregar os SIG's e a metodologia aqui utilizada não implicaria em trabalhos adicionais, apenas seria uma base de dados maior.

O fato de se trabalhar com critérios que possuem uma delimitação espacial e a sua integração, remove de maneira eficiente a subjetividade na escolha dos locais para a implantação, fato que poderia gerar conflitos entre os gestores e a população local, bem como direciona para uma maior sustentabilidade ambiental nestes empreendimentos.

\section{REFERÊNCIAS}

ASSOCIAÇÃO BRASILEIRA DE EMPRESAS DE LIMPEZA PÚBLICA E RESÍDUOS ESPECIAIS (ABRELPE). Panorama de resíduos sólidos no brasil- 2014. São Paulo: AbreIpe, 2015.

ABNT, ASSOCIAÇÃO BRASILEIRA DE NORMAS TÉCNICAS. NBR 8419: Apresentação de projetos de aterros sanitários de resíduos sólidos urbanos - procedimento. Rio de Janeiro, 1992.

ABNT, ASSOCIAÇÃO BRASILEIRA DE NORMAS TÉCNICAS. NBR 13896: Aterros de resíduos não perigosos - Critérios para projeto, implantação e operação. Rio de Janeiro, 1997.

AMARAL, D. G. P., LANA, C. E.. Uso de geoprocessamento para indicação de áreas favoráveis à construção de aterro sanitário no município de Ouro Preto (MG). Caderno de Geografia, v.27, n.49, p. 368-382, 2017.

BAHRANI, S.; EBADI, T.; EHSANI, H.; YOUSEFI, H.; MAKNOON, R.. Modeling landfill site selection by multi-criteria decision making and fuzzy functions in GIS, case study: Shabestar, Iran. Environmental Earth Sciences, v.75, n.4, p. 337, 2016.

BENDA, F.. Favorabilidade de áreas para implantação de aterros controlados no município de Campos dos Goytacazes/RJ utilizando Sistemas de Informação Geográfica. 
Dissertação de mestrado em Engenharia Civil, Universidade Estadual do Norte Fluminense, Campos dos Goytazes, 2015.

BESKESE, A.; DEMIR, H.H.; OZCAN, H.K.; OKTEN, H.E. Landfill site selection using fuzzy AHP and fuzzy TOPSIS: a case study for Istanbul. Environmental Earth Sciences, v.73, n.7, p. 3513-3521, 2015.

BRASIL. Lei n. 12.305, de 2 de agosto de 2010. Política nacional de resíduos sólidos. - 2 . ed. - Brasília: Câmara dos Deputados, Edições Câmara, 2012. 73 p. - (Série legislação ; n. 81).

CALIJURI, M. L.; LOURES, S. S. P.; SANTIAGO, A. F.; SCHAEFER, C. E. G. R.; LUGÃO, W. G.; ALVES, J. E. M.. Identificação de áreas alternativas para disposição de resíduos sólidos na região do Baixo Ribeira do Iguape - SP. Engenharia Sanitária \& Ambiental. V.12, n. 3, p. 335-342, 2007.

FELICORI, T. C.; MARQUES, E. A. G.; SILVA, T. Q.; PORTO, B. B.; BRAVIN, T. C.; SANTOS, K. M. C.. Identificação de áreas adequadas para a construção de aterros sanitários e usinas de triagem e compostagem na mesorregião da Zona da Mata, Minas Gerais. Engenharia Sanitária \& Ambiental, v.21, n3, p. 547-560, 2016.

GOMES, R. L; MARQUES, E. A.; FRANCO, G. B.. Aptidão da Bacia Hidrográfica do Rio Almada diante da implantação de áreas para disposição ambiental de rejeitos. Engenharia Sanitária \& Ambiental, v.22, n.4, p.731-747, 2017.

GONÇALVES, M. A.; VALE, M. M. A. A. V.Q.; GONÇALVES, A. H.. Um Estudo Comparado entre a Realidade Brasileira e Portuguesa sobre a Gestão dos Resíduos Urbanos. Sociedade \& Natureza, v.28, n.1, p. 9-20, 2016.

INSTITUTO BRASILEIRO DE GEOGRAFIA E ESTATÍSTICA (IBGE). (2013) Projeção da população do Brasil por sexo e idade para o período de 2000 / 2060. Disponível em: < ftp://ftp.ibge.gov.br/Projecao_da_Populacao/Projecao_da_Populacao_2013/nota_metodologica_2013.pdf>. Acesso em: 01 jul. 2018.

INSTITUTO BRASILEIRO DE GEOGRAFIA E ESTATÍSTICA (IBGE). (2018) Itabira. Disponível em: https://cidades.ibge.gov.br/brasil/mg/itabira/panorama. Acesso em: 05 jun. 2018.

ISALOU, A.A.; ZAMANI, V.; SHAHMORADI, B.; ALIZADEH, H.. Landfill site selection using integrated fuzzy logic and analytic network process (F-ANP). Environmental Earth Sciences, v. 68, n. 6, p. 1745-1755, 2013.

KHAN, D.; SAMADDER, S. R.. Municipal solid waste management using Geographical Information System aided methods: a mini review. Waste Management \& Research, v.32, n.11, p. 1049-1062, 2014.

MARCHI, C. M. D. F.. Novas perspectivas na gestão do saneamento: apresentação de um modelo de destinação final de resíduos sólidos urbanos. Revista Brasileira de Gestão Urbana, v.7, n.1, p. 91-105, 2015.

MINAS GERAIS. Lei no 18.031, de 12 de janeiro de 2009. Política Estadual de Resíduos Sólidos. Belo Horizonte. Disponível em: http://www.siam.mg.gov.br/sla/download.pdf?idNorma=9272. Acesso em: 01 jul. 2018. 
MINISTÉRIO DO MEIO AMBIENTE - MMA (2010). Lei 12.305 - Política nacional de resíduos sólidos. Disponível em: http://www.mma.gov.br/pol\%c3\%adtica-de-res\%c3\%adduoss\%c3\%b3lidos. Acesso em: 05 jun. 2018.

OHRI, A.; SINGH, P. K.. GIS based environmental decision support system for municipal landfill site selection. Management of Environmental Quality, v.24, n.583, p. 598, 2013.

PREFEITURA MUNICIPAL DE ITABIRA. Arquivos de Tag: aterro sanitário. 2018. Disponível em: http://www.itabira.mg.gov.br/portal/?tag=aterro-sanitario. Acesso em: 05 jun.

2018.

REZAEIMAHMOUDI, M.; ESMAELI, A.; GHAREGOZLU, A.; SHABANIAN, H.; ROKNI, L.. Application of geographical information system in disposal site selection for hazardous wastes. Journal of Environmental Health Science \& Engineering, v.12, p.141, 2014.

REVISTA BRASIL MINERAL. Mineração de ferro em Itabira (mg) deixa passivo socioambiental e econômico.2013. Disponível em: http://verbetes.cetem.gov.br/verbetes/exibeverbete. $a s p x$ ?verid=60. Acesso em: 05 jun. 2018 